\title{
Numerical simulation research on steel/ceramic composite target plate structure against penetration of high-speed projectile
}

\author{
Gang Wu' ${ }^{1}$ Xin Wang ${ }^{2}$, Xiaofei $\mathrm{Lu}^{3}$, Chong $\mathrm{Ji}^{4}$, Changxiao Zhao ${ }^{5}$, Haojie Zhu ${ }^{6}$ \\ ${ }^{1,2,4,5,6}$ College of Field Engineering, Army Engineering University of PLA, Nanjing, 210007, China \\ ${ }^{3}$ Jiuquan Satellite Launching Center, Gansu Lanzhou 732750, China \\ ${ }^{4}$ Corresponding author \\ E-mail:1392520073@qq.com, ${ }^{2} 310433804 @ q q . c o m,{ }^{3}$ luxf08@163.com, ${ }^{4} 2468645816 @ q q . c o m$,

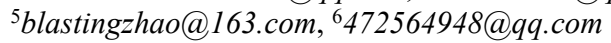

Received 11 October 2020; received in revised form 22 October 2020; accepted 28 October 2020 DOI https://doi.org/10.21595/vp.2020.21734

Check for updates

Copyright $(2020$ Gang Wu, et al. This is an open access article distributed under the Creative Commons Attribution License, which permits unrestricted use, distribution, and reproduction in any medium, provided the original work is properly cited.

\begin{abstract}
This study is mainly based on LS-DYNA to simulate the entire process of high-speed projectile penetration into the steel-ceramic composite target structure. In the process of projectile penetration into the target, the impact speed of projectile, the structure of steel-ceramic composite target plate and other key factors on the target failure and target transient response and the law are explored. The article tried different thickness combinations of the steel plate ceramic structure, obtained the best thickness combination according to the after-effect of penetration, and analyzed the remaining velocity and remaining rod length of the projectile. The results show that the composite target plate has the best protection performance under the condition of the thickness ratio of panel-sandwich-back plate of $1: 2: 1$, and the composite target plate has better anti-penetration performance against projectiles with a speed greater than $1500 \mathrm{~m} / \mathrm{s}$.
\end{abstract}

Keywords: steel/ceramic composite structure, numerical simulation, projectile velocity.

\section{Introduction}

Ceramic materials have excellent mechanical and physical properties due to corrosion resistance, high temperature resistance, wear resistance, and low density compared to steel materials, in the field of high-tech national defense, such as aircraft, ships, vehicles and other key parts of the bulletproof shielding layer and the protection of individual combat is widely used. Although ceramic materials have unique advantages that are irreplaceable compared with other materials. However, its brittleness hinders its wider use. The improved method is mainly composite. The composite armor structure composed of ceramic panels and metal back panels has the advantages of light weight, excellent elasticity resistance and corrosion resistance, and has been widely used. It has excellent ballistic properties (including penetration resistance, impact resistance and avalanche resistance). Compared with conventional armor materials such as metal and glass fiber reinforced plastics, its ballistic resistance is significantly improved.

Many scholars have carried out in-depth research on ceramic composite structures. For a double-layer ceramic/metal target plate of a given material and areal density, Hetherington [1] used the Florence model to obtain an approximate solution for the optimal matching of the thickness of the panel and backplane. Mastilovics [2] used the dynamic cavity expansion model to study the anti-penetration performance of ceramic materials, derived the calculation formula of the minimum surface density of the target plate and the thickness of the corresponding panel and back plate, and compared the results with the existing test data. Satapathy [3] proposed an oblique impact model using the theory of cavity expansion, and gave the ballistic response analysis of the ceramic plate. The analysis results show that the anti-penetration resistance of ceramic materials mainly depends on the strength properties of crushed ceramics, and the ballistic limit velocity varies as the impact slope increases. Xiao-qing Zhang [4] Considered the rough deformation of the projectile body during the penetration process, the fracture of the ceramic panel, the formation 
of the ceramic cone and the deformation of the metal back plate, the theoretical analysis of the deformable projectile's vertical penetration into the ceramic/metal target plate was established. Zhao Guozhi [5] uses the energy method to establish a theoretical model of the dynamic response of the thin plate under impact load, and gives the limit velocity of the ballistic.

Many scholars have conducted research on steel/ceramic composite structures, most of them focus on the effect of composite structure composition on armor penetration efficiency, and lack of research on the impact of projectile velocity and target plate thickness composition on armor penetration efficiency. This paper numerically simulates the interaction performance of projectiles at different speeds penetrating the steel/ceramic structure, analyzes the thickness composition of the target plate and the impact of projectile velocity on the penetration efficiency, and provides references for the optimization design and improvement of composite structures.

\section{Calculation model}

As shown in Fig. 1, the commercial finite element software LS-DYNA was used to carry out a numerical simulation study of high-speed projectile penetration into steel/ceramic target plates of different thicknesses. The target plate uses $45 \#$ steel uniformly, the ceramic is AD95-A12O3 ceramic, and the projectile material uses tungsten alloy. Both the steel rod-shaped projectile and the steel/ceramic composite structure are meshed using the Lagrange model. Due to the symmetry of the research problem, in order to save calculation time, only a quarter model is established. Appropriate boundary conditions are applied along the symmetry plane, symmetrical constraints are set on the symmetrical surface, and fixed constraints are set on the outside of the asymmetrical boundary. The projectile penetrates the steel/ceramic composite target plate vertically at different speeds. The parameters of the projectile and the target plate are shown in Table 1.
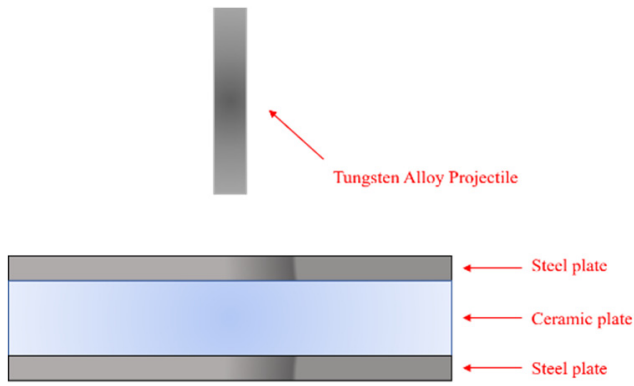

Fig. 1. The numerical model

Table 1. The parameters of the projectile and the target plate

\begin{tabular}{|c|c|c|c|c|c|}
\hline $\begin{array}{c}\text { Working } \\
\text { condition }\end{array}$ & $\begin{array}{c}\text { Panel } \\
\text { thickness }\end{array}$ & $\begin{array}{c}\text { Backboard } \\
\text { thickness }\end{array}$ & $\begin{array}{c}\text { Ceramic plate } \\
\text { thickness }\end{array}$ & $\begin{array}{c}\text { Projectile radius } \\
\text { and height }\end{array}$ & $\begin{array}{c}\text { Projectile } \\
\text { velocity }\end{array}$ \\
\hline $\mathrm{A}$ & $5 \mathrm{~mm}$ & $25 \mathrm{~mm}$ & $30 \mathrm{~mm}$ & $10 \mathrm{~mm} \times 50 \mathrm{~mm}$ & $1500 \mathrm{~m} / \mathrm{s}$ \\
\hline $\mathrm{B}$ & $10 \mathrm{~mm}$ & $20 \mathrm{~mm}$ & $30 \mathrm{~mm}$ & $10 \mathrm{~mm} \times 50 \mathrm{~mm}$ & $1500 \mathrm{~m} / \mathrm{s}$ \\
\hline $\mathrm{C}$ & $15 \mathrm{~mm}$ & $15 \mathrm{~mm}$ & $30 \mathrm{~mm}$ & $10 \mathrm{~mm} \times 50 \mathrm{~mm}$ & $1500 \mathrm{~m} / \mathrm{s}$ \\
\hline $\mathrm{D}$ & $20 \mathrm{~mm}$ & $10 \mathrm{~mm}$ & $30 \mathrm{~mm}$ & $10 \mathrm{~mm} \times 50 \mathrm{~mm}$ & $1500 \mathrm{~m} / \mathrm{s}$ \\
\hline $\mathrm{E}$ & $25 \mathrm{~mm}$ & $5 \mathrm{~mm}$ & $30 \mathrm{~mm}$ & $10 \mathrm{~mm} \times 50 \mathrm{~mm}$ & $1500 \mathrm{~m} / \mathrm{s}$ \\
\hline $\mathrm{F}$ & $15 \mathrm{~mm}$ & $15 \mathrm{~mm}$ & $30 \mathrm{~mm}$ & $10 \mathrm{~mm} \times 50 \mathrm{~mm}$ & $900 \mathrm{~m} / \mathrm{s}$ \\
\hline $\mathrm{G}$ & $15 \mathrm{~mm}$ & $15 \mathrm{~mm}$ & $30 \mathrm{~mm}$ & $10 \mathrm{~mm} \times 50 \mathrm{~mm}$ & $1100 \mathrm{~m} / \mathrm{s}$ \\
\hline $\mathrm{H}$ & $15 \mathrm{~mm}$ & $15 \mathrm{~mm}$ & $30 \mathrm{~mm}$ & $10 \mathrm{~mm} \times 50 \mathrm{~mm}$ & $1300 \mathrm{~m} / \mathrm{s}$ \\
\hline $\mathrm{I}$ & $15 \mathrm{~mm}$ & $15 \mathrm{~mm}$ & $30 \mathrm{~mm}$ & $10 \mathrm{~mm} \times 50 \mathrm{~mm}$ & $1500 \mathrm{~m} / \mathrm{s}$ \\
\hline $\mathrm{J}$ & $15 \mathrm{~mm}$ & $15 \mathrm{~mm}$ & $30 \mathrm{~mm}$ & $10 \mathrm{~mm} \times 50 \mathrm{~mm}$ & $1800 \mathrm{~m} / \mathrm{s}$ \\
\hline $\mathrm{K}$ & $15 \mathrm{~mm}$ & $15 \mathrm{~mm}$ & $30 \mathrm{~mm}$ & $10 \mathrm{~mm} \times 50 \mathrm{~mm}$ & $2100 \mathrm{~m} / \mathrm{s}$ \\
\hline $\mathrm{L}$ & $15 \mathrm{~mm}$ & $15 \mathrm{~mm}$ & $30 \mathrm{~mm}$ & $10 \mathrm{~mm} \times 50 \mathrm{~mm}$ & $2300 \mathrm{~m} / \mathrm{s}$ \\
\hline $\mathrm{M}$ & $15 \mathrm{~mm}$ & $15 \mathrm{~mm}$ & $30 \mathrm{~mm}$ & $10 \mathrm{~mm} \times 50 \mathrm{~mm}$ & $2500 \mathrm{~m} / \mathrm{s}$ \\
\hline $\mathrm{O}$ & $15 \mathrm{~mm}$ & $15 \mathrm{~mm}$ & $30 \mathrm{~mm}$ & $10 \mathrm{~mm} \times 50 \mathrm{~mm}$ & $2700 \mathrm{~m} / \mathrm{s}$ \\
\hline
\end{tabular}




\section{Results and analysis}

\subsection{The influence of different surface/back thickness on the anti-penetration ability of composite target}

Numerical analysis of the projectile penetrating the target under the conditions of A, B, C, D and $\mathrm{E}$. The deformation of the target plate and the projectile is shown in Fig. 2.

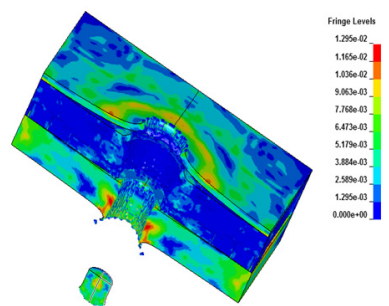

a) A

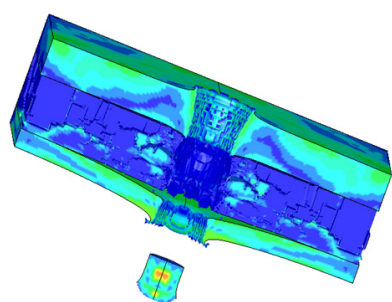

d) $\mathrm{D}$

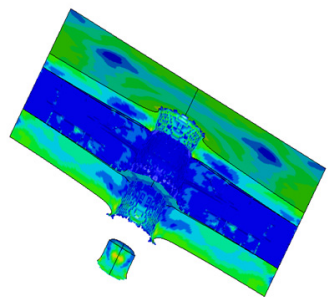

b) $\mathrm{B}$

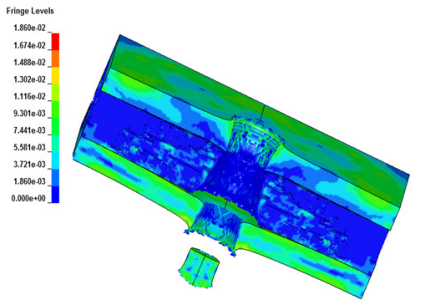

c) $\mathrm{C}$

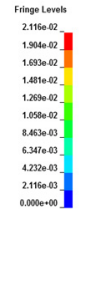

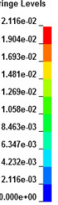

Fig. 2. The deformation of the target plate and the projectile body

It can be seen from Fig. 2 that after the projectile penetrates the composite structure, the remaining length of the rod gradually becomes shorter, but there is a residual velocity. Cracks appear on the surface of the ceramic plate, which means that it has absorbed part of the energy through the fragmentation of the structure. Fig. 3 shows the remaining velocity of the projectile after penetration under the conditions of A, B, C, D and E. It can be seen that with the gradual increase in the thickness of the target plate on the front surface, the remaining velocity of the projectile first decreases and then increases. When the business speed is the smallest, it reaches $812 \mathrm{~m} / \mathrm{s}$. This shows that when the total thickness of the target board is $60 \mathrm{~mm}$, the composite target board with the target board thickness of $15 \mathrm{~mm}$ on the front surface and $15 \mathrm{~mm}$ on the back surface has the best anti-penetration ability.

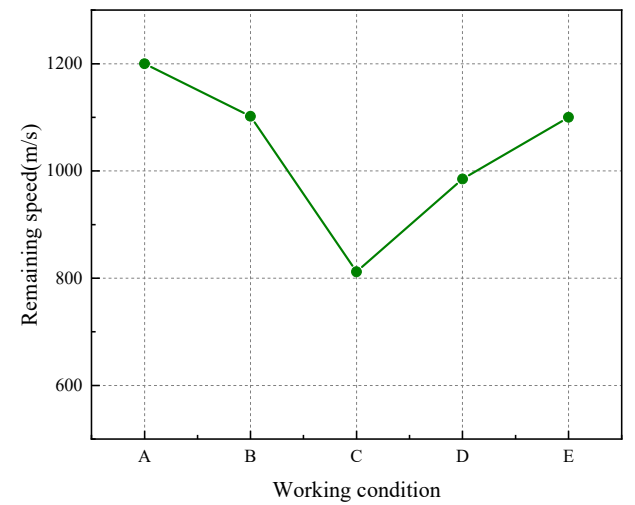

Fig. 3. The remaining speed after the projectile penetrates 


\subsection{Analysis of anti-penetration ability of composite target plate at different penetration speed}

The penetration of the high-speed projectile into the working condition F-O is shown in Fig. 4. Table 2 shows the remaining velocity and length of the projectile after penetrating the target. Fig. 5 shows the attenuation ratio of the remaining amount to the initial amount.

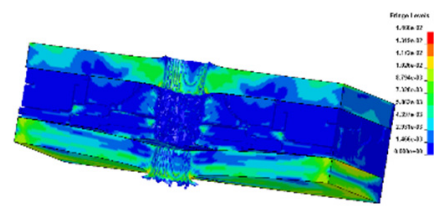

a) $\mathrm{A}$

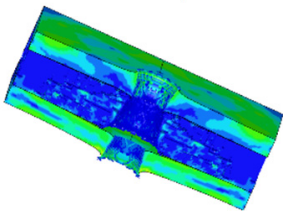

d) $\mathrm{D}$

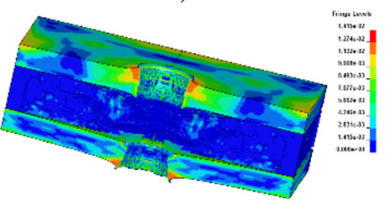

g) $\mathrm{G}$

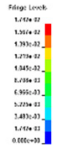

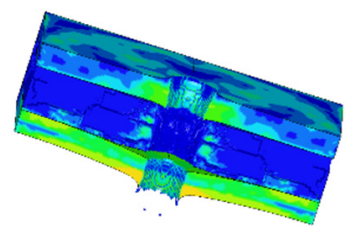

b) $\mathrm{B}$

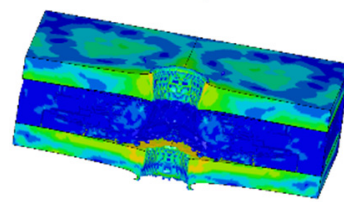

e) $\mathrm{E}$

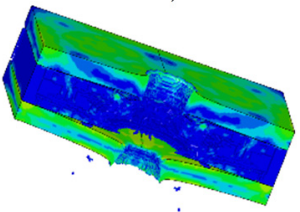

h) $\mathrm{H}$
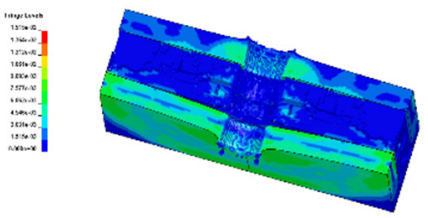

c) $\mathrm{C}$
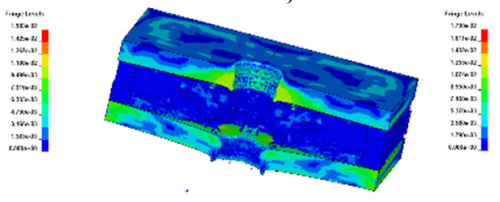

f) $F$
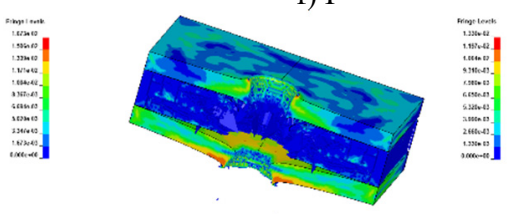

i) I

Fig. 4. The deformation of the target plate and the projectile body

Table 2. Remaining speed and remaining length

\begin{tabular}{|c|c|c|c|}
\hline Initial velocity $(\mathrm{m} / \mathrm{s})$ & Remaining speed $(\mathrm{m} / \mathrm{s})$ & Initial length $(\mathrm{cm})$ & Remaining length $(\mathrm{cm})$ \\
\hline 900 & 570 & 5 & 3.242 \\
\hline 1100 & 794 & 5 & 2.567 \\
\hline 1300 & 900 & 5 & 2.010 \\
\hline 1500 & 111.5 & 5 & 1.477 \\
\hline 1800 & 194.9 & 5 & 1.469 \\
\hline 2100 & 229.2 & 5 & 0.799 \\
\hline 2300 & 277.2 & 5 & 0.782 \\
\hline 2500 & 100.7 & 5 & 0.817 \\
\hline 2700 & 357.1 & 5 & 0.576 \\
\hline
\end{tabular}

It can be seen from Table 2 and Fig. 5 that when the initial velocity of the projectile is less than $1500 \mathrm{~m} / \mathrm{s}$, the remaining length of the projectile decreases with the increase of the incident velocity, but the remaining velocity does not change much. The overall trend is compared Stable, when the incident velocity of the projectile is between $1500 \mathrm{~m} / \mathrm{s}-1800 \mathrm{~m} / \mathrm{s}$, there is a sudden change in the remaining velocity, and the projectile wears more serious, and the remaining length becomes smaller. When the incident velocity is greater than $1800 \mathrm{~m} / \mathrm{s}$, the residual velocity is very small. The balance ratio tends to be stable, and the length of the projectile becomes smaller as the speed increases. And it is known from the previous section that when the incident speed is less than $1500 \mathrm{~m} / \mathrm{s}$, it is easier to produce fragments and increase the killing performance of the projectile. Therefore, the composite target plate has better anti-penetration performance against projectiles with a speed greater than $1500 \mathrm{~m} / \mathrm{s}$. 


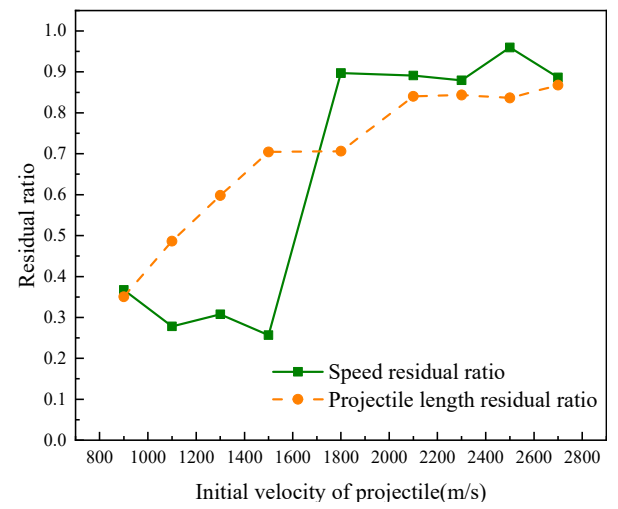

Fig. 5. Attenuation ratio of remaining quantity to initial quantity

\section{Conclusions}

1) The damage range of ceramic materials is large, and the damage mode is different from the plastic rheology of metal materials. The ceramic interlayer undergoes brittle fracture, and its crushing absorbs part of the energy of the projectile. Therefore, the ceramic/steel composite target plate can improve the protective ability of the armor.

2) As the thickness ratio of the ceramic-to-metal material increases, the remaining velocity and remaining mass of the projectiles show a trend of decreasing first and then increasing. Under the condition that the ceramic interlayer is $30 \mathrm{~mm}$, the protection performance of the front panel, interlayer and backplane is the best under the condition of the thickness ratio of 1:2:1.

3) When the thickness ratio of the front panel, ceramic interlayer and backplane is $1: 2: 1$, it has better protection against projectiles with a penetration speed of more than $1500 \mathrm{~m} / \mathrm{s}$.

\section{Acknowledgements}

This research was financially supported by the National Nature Science Foundation of China, Nos. 51978660.

\section{References}

[1] Hetherington J. G. Energy and momentum changes during ballistic perforation. International Journal of Impact Engineering, Vol. 18, Issue 3, 1996, p. 319-337.

[2] Mastilovic S., Krajcinovic D. High velocity expansion of a cavity with a brittle material. Journal of Mechanics Physics Solids, Vol. 47, 1999, p. 577-610.

[3] Satapath Y. S. Dynamic spherical cavity expansion in brittle ceramic. International Journal of Solids Structures, Vol. 38, 2001, p. 5833-5845.

[4] Zhang Xiao-Qing Study on ceramic/metal armor penetrated by projectile. Engineering Mechanics, Vol. 23, Issue 4, 2006, p. 155-159.

[5] Zhao Guozhi A simplified model for projectile normally into ceramic/metal composite target. Journal of Ballistics, Vol. 13, 2, p. 13-17. 